\title{
A Developmental Analysis of Children's and Adolescents' Understanding of Luck and Ability in the Physical Domain
}

\author{
Mary D. Fry \\ University of Memphis
}

\begin{abstract}
Using Nicholls' developmental component as a framework, the purpose of this study was to examine children's understanding of luck and ability in the physical domain. Children ( $N=144,8$ boys and 8 girls at each age from 5 to 13 years) enrolled in public schools participated individually in a 30-min session in which they were shown 2 similar games; one required luck and the other required skill to perform successfully. Participants received an explanation of the games and were told of youngsters who had tried unsuccessfully to play them. Participants were interviewed, and their responses were analyzed via a Piagetian structural developmental method. Results revealed that the 4 levels of understanding of luck and ability Nicholls and Miller (1985) described were relevant to the physical domain. Furthermore, the Spearman rho coefficient indicated a strong positive relationship between children's age and their level of understanding of luck and ability.
\end{abstract}

Key words: goal perspective theory, cognitive development

Recent investigations in the physical domain have examined two of the three aspects of the developmental component of Nicholls' (1989) theory of achievement motivation. Specifically, children's understanding of effort and ability (Fry \& Duda, 1997; Fry, Lattimore, \& Balas, 1999) and task difficulty (Fry, in press) have been studied and have revealed results similar to those reported by Nicholls (1978) in the academic domain. However, children's understanding of luck and ability has yet to receive attention in the physical domain and was thus the focus of this article.

Nicholls' (1989) theory of achievement motivation provides a framework for considering individuals' motivational perspectives across the life span. Nicholls suggested that cognitive developmental processes are particularly important during the childhood years, when youngsters are learning the meaning of critical concepts related to achievement. He theorized that around the age of 12 years, children gain a mature understanding of ability in which they ascertain that high ability is evident when individuals exert less effort and outperform others. To reach this level of development, Nicholls explained, children must gain an understanding of

Mary Fry is with the Department of Human Movement Sciences and Education at the University of Memphis, Memphis, TN 38152. 
three concepts. They must be able to distinguish luck from ability, effort from ability, and normative task difficulty; this process is gradual in that the concepts become more and more differentiated over time.

In terms of luck and ability, Nicholls and Miller (1985) identified four levels that children progress through as they develop a mature understanding of these concepts. At Level 1, children do not distinguish characteristics of tasks that require luck as opposed to skill. They indicate that effort will maximize performance on both skill and luck tasks, and they do not perceive that an individual is more likely to be successful when participating in an activity that requires skill rather than luck. At Level 2, children recognize that success is harder to achieve on luck tasks than on skill tasks, but they still believe that effort will enhance performance on activities requiring either skill or luck. Level 3 represents a transitional period in which children are very close to fully distinguishing luck from ability. At this level, they provide reasoning that is evident of Level 4, yet they lack consistency in their reasoning across the interview, and a portion of their responses regress back to reflect Level-1 or -2 criteria. At Level 4 , children achieve a mature understanding of luck and ability, recognizing that effort enhances performance on tasks requiring skill but is not helpful in improving performance on activities requiring luck.

Nicholls and Miller's (1985) approach to investigating these cognitive processes was quite unique in that they presented children with similar activities in which success stemmed from either luck or skill. Most important in this approach were the visual stimuli presented to the children (Nicholls, 1989, 1990); that is, Nicholls and Miller did not rely only on oral communication to describe the games to the children. Instead, the youngsters were able to touch, see, and experience the activities for themselves. Specifically, children were presented six figures, each on a separate card, and the aim was to identify the figure that matched the seventh card, which was the standard. In the luck version of the game, the six figure cards were turned face down, but on the skill game the figure cards lay face up. Children were told of youngsters who had performed the task, some of whom had been successful and others who had been unsuccessful. Nicholls and Miller then asked the children questions about the different youngsters' outcomes on the task, giving them opportunities to explain the results and to speculate on future outcomes. Children's responses to questions about the two activities led Nicholls and Miller to identify the four levels of differentiation of luck and ability that children experience. The researchers found that most kindergarten-age children displayed Level1 and Level-2 reasoning. Second graders had considerable variability in their ratings (i.e., primarily Levels 1-3), and fourth and sixth graders demonstrated reasoning mostly characteristic of Levels 3 and 4 . By eighth grade, 90\% of the students displayed Level -4 reasoning.

In order to validate their qualitative analyses of the children's understanding of luck and ability, Nicholls and Miller (1985) had the children play six rounds of either the luck or the skill activity, in which they attempted to identify the figure that matched the standard. The researchers were able to ensure that the children were unsuccessful on the activities by having very slight differences on all the figures, so that each was an incorrect match for the standard. When a child identified the figure he or she thought matched the standard, the experimenter showed the child the feature that differed from the standard and quickly proceeded to the next round. Afterward, the children were given another opportunity to participate 
in the games, and this time they were all more successful. By asking the children why they were able to achieve greater success the second time around, Nicholls and Miller acquired information about their understanding of luck and ability. For example, younger children attributed their outcomes on both games to effort and ability, whereas the older students attributed success on the luck task to luck and success on the skill task to effort and ability. This portion of the design helped validate the ratings of the children's levels of understanding of luck and ability by providing evidence that the levels of reasoning were related to children's cognitive responses.

Further support for the children's levels of understanding of luck and ability was evident on examining the time periods children spent on the luck and skill tasks, respectively. In comparison with youngsters at Levels 1-3, children at Level 4 spent the most time on the skill tasks and the least time on the luck tasks. In contrast, children rated at Level 1 spent a greater amount of time on the luck than the skill tasks. This makes sense when one considers that children at Level 1 do not recognize the difference between the two activities, and children at Level 2 believe that their high effort will allow them to do well on luck and skill tasks. Overall, children rated at Level 4 appeared to enjoy the skill task more than the luck task, as was evident in their spending more time on it. In addition, it would follow that, if given an opportunity to engage in the tasks again, children at Level 4 would likely indicate a preference for the skill rather than the luck task because they would have more control over the outcome.

Nicholls $(1989,1990)$ maintained that the investigation of children's differentiation of luck and ability is an important area of inquiry because it affects youngsters' development of achievement motivation. As children differentiate the concepts of luck, effort, ability, and task difficulty (i.e., obtain a mature understanding of ability), they are developing their dispositional goal orientations (task and ego), or personal definitions of success. When individuals are high in task orientation, they gauge success by their personal effort and improvement. According to Nicholls (1989), young children have a natural propensity to be task oriented because of their lack of cognitive maturation, in terms of distinguishing ability from effort and luck, as well as of understanding normative task difficulty. Recent research in the physical domain has revealed that most young children see effort as the primary determinant of ability and performance (Fry \& Duda, 1997).

Ego orientation is marked by the view that success is achieved when an individual attains favorable performance outcomes and/or high normative standing among peers. Thus, in order to be ego oriented, individuals must be able to accurately judge their ability in comparison with their peers. Research in the physical domain suggests that children lack the cognitive skills to do this until the later elementary years (Fry, in press; Fry \& Duda, 1997; Horn \& Weiss, 1991). For example, the capacity to accurately judge ability requires that individuals recognize the roles that skill and luck play in performance. If children believe that effort maximizes performance on tasks that require skill and luck, they lack the cognitive understanding necessary to be ego oriented.

Nicholls identified the formation of task and ego goal orientations as an important developmental process because of their link with different affective, cognitive, and behavioral motivational responses in achievement settings. Overall, a task orientation has been associated with a profile of more adaptive motivational responses in the physical domain, including high effort and enjoyment (see 
Duda \& Whitehead, 1998, for a review). If a mature understanding of ability is required before an individual can fully adopt an ego orientation, the developmental and psychological influences that shape this orientation are very important to identify. Based on this knowledge, appropriate physical activity opportunities could be provided to minimize youngsters' ego orientation and maximize their task orientation.

The purpose of this study, therefore, was to use Nicholls' developmental framework to examine children's understanding of luck and ability in the physical domain. The four levels of understanding of luck and ability identified by Nicholls and Miller (1985) in the academic domain were hypothesized to be relevant in the physical domain. In addition, the structural nature of the levels, as well as the timing of children's progression through the levels, was predicted to be similar to that reported by Nicholls and Miller. Nicholls (1992) suggested that the levels of cognitive reasoning being assessed should not be greatly affected by the nature of the task used to examine the developmental concepts in his framework. That is, whether the specific task involves solving puzzles, doing math problems, or throwing bean bags, children's cognitive reasoning should remain relatively stable across tasks. Fry and Duda (1997) found this to be the case when comparing children's levels of understanding of effort and ability in the academic (i.e., using math problems) and physical (i.e., throwing beanbags at targets) domains. In addition, Nicholls and Miller reported no gender differences, and none were predicted in this study.

Finally, in order to validate the ratings of the children's understanding of luck and ability, it was hypothesized that when provided an opportunity to play games requiring skill and/or luck, children who were rated at Level 4 (i.e., who reflected mature reasoning of luck and ability) would demonstrate the following responses: They would (a) spend a greater amount of time playing the game that required skill for success, (b) indicate that the skill game was more fun, and (c) indicate that, if given the opportunity to play the games again on another day, they would prefer to play the skill game. These responses were predicted because children who demonstrate a mature understanding of luck and ability realize that they have no control over the outcome on luck tasks and would likely prefer to determine, as much as possible, the course of their actions.

\section{Method}

\section{Procedure}

Students ( $N=144,8$ boys and 8 girls at each age from 5 to 13 years) from public schools volunteered to participate in this study. They came from predominantly middle-class backgrounds, and approximately $80 \%$ were White, with the other $20 \%$ being Black or Asian.

Permission to conduct this study was obtained from the researcher's university internal review board, public school district administrators, school administrators, and teachers. The recruiting strategy preferred by the principals was that the investigator visit individual classrooms and briefly describe the study to students. Interested students (i.e., those who raised their hands) were then given a parental consent form and were scheduled to participate in the project only after the form was returned to the school. The students were told that because of time 
constraints only the first 8 boys and 8 girls (at each age) who returned their consent forms would be included in the study. Children who returned the consent form within 3 weeks of its distribution participated fully in the study.

Children were individually escorted from their class to a room in which they participated in an approximately 30-min session to assess their level of understanding of luck and ability. The interviewer took notes, and each interview was audiotaped in the case that further review of the child's responses might be necessary. The investigator conducted all interviews. After the sessions, children were escorted back to their classrooms. Each child participated in a second session designed to determine his or her level of understanding of task difficulty, which is presented in a separate article because of its length (see Fry, in press).

Each child received a certificate acknowledging his or her outstanding participation in the study.

\section{Data-Collection Procedure}

Children were shown two similar games, one requiring luck for success and the other requiring skill. Each game consisted of a deck of cards and four black baskets; each card and basket had a brightly colored star (pink, green, orange, or yellow) emblazoned on it. The decks of cards were on a small table about $5 \mathrm{ft}$ away from the line of baskets, and there was a chair on each side of the table.

In the skill game, a child drew a card from the deck and attempted to throw a beanbag into the basket that corresponded to the color of the star on the card. In the luck game, the child tried to guess what color star the next card in the deck would be and to throw the beanbag into the appropriate basket; the child then drew the card to determine whether he or she had guessed correctly. Participants received an introduction to and demonstration of the two games, and then, to check their understanding of them, they were asked to explain the rules of each game to the interviewer. Next, the participants were told of a child (Max or Beth) who was unsuccessful on the luck game and another child (Dale or Peggy) who was unsuccessful on the skill game. Girls' names were used for female participants, and boys' names were used for male participants. Children were told the following:

Now I want to show you how some other children did on these games. I'll show you what different children did. First of all, on this game [luck], a boy named Max (a girl called Beth) threw the beanbag in the pink basket, but then he (she) drew an orange card. So he (she) didn't get a point. He (she) didn't get it right. And a boy named Dale (a girl named Peggy) chose a green card, but he (she) threw the beanbag in the yellow basket, so he (she) didn't get a point. He (she) didn't get it right. [Wrong responses are demonstrated.] Can you see that they both got it wrong?

Next, children were asked the following questions in order to determine their level of understanding of luck and ability: (1) Do you think both boys (girls) could have gotten their beanbag in the right basket? (2a) What if they tried harder or were more careful? ( $2 b$ ) So could Max (Beth) have gotten the beanbag in the right basket if he (she) had tried harder? (2c) How can you tell? (2d) And could Dale (Peggy) have gotten the beanbag in the right basket if he (she) tried harder? (2e) 
How can you tell? (3a) If they both play the game again and try their hardest, which boy (girl) will most likely get the beanbag in the right basket? (3b) Why do you think so?

After each child responded to the interview questions, the investigator thanked the child for his or her participation in the study, and then she looked at her watch and commented that there was time left for the child to play the games. She told the children the following:

[Name of child], thanks a lot for your help with our study. Those were really good answers you gave. You know, we have some time left and so I'd like to give you a chance to play the games and see what you think. How does that sound? Okay, do you remember the rules of the two games? [The investigator would have the child verbally explain the rules of each game to ensure that he or she could still distinguish the two games.] Great. Well, you will have about 5 minutes to play the games, and you can play one game the whole time, or the other game the whole time, or you can switch back and forth. You can do whatever you want. The only thing I ask is that you follow the rules of each game, so if you're playing this game [pointing to skill game baskets], you will draw the card first and then throw the beanbag and if you're playing this game [pointing to luck game baskets], you will throw the beanbag first and then draw the card. Okay? While you're playing the games I'm going to fill in the rest of my notes.

The child proceeded to play the games, while the investigator pretended to be busy writing on her clipboard and appeared to be paying no attention to the child. Actually, she had a stopwatch and was keeping track of how much time the child spent playing each of the games during the 5-min period. Afterward, the child was asked the following questions: (a) Which game did you play the longest? Why? (b) Which game was the most fun? Why? (c) If you could come back and play one of these games again on another day, which game would you choose? Why?

\section{Pilot Study}

A pilot study with 15 children varying in age from 5 to 13 years was conducted to ensure that the games and questions were appropriate for and understood by youngsters in the targeted age group. The pilot study revealed no problem areas in the procedure.

\section{Independent Raters}

The investigator trained three graduate students to rate the children's levels of understanding of luck and ability. Their training consisted of the following: (a) They read several of Nicholls' developmental articles, (b) they were provided examples of each of the levels of understanding of luck and ability and discussed them with the investigator, and (c) they participated in two practice rounds in which they scored sample responses. When the training was completed, one graduate student rated all 144 of the children's responses, and the other two raters independently scored a randomly selected sample of 25 of the children's responses. 


\section{Results}

\section{Structural Developmental Analysis}

A Piagetian structural developmental analysis of the children's responses to the interview questions was conducted to determine the children's levels of understanding of luck and ability (Piaget, 1952; Piaget \& Inhelder, 1975). This approach was identical to that used by Nicholls in previous research $(1978,1989$; Nicholls $\&$ Miller, 1985). Sample responses of children at each of the four levels are provided below and are representative of the reasoning that youngsters displayed at each level.

Level 1. Level-1 reasoning dominated among the youngest children, with only 2 children above the age of 9 years being rated at Level 1. At Level 1, children made no distinction between the luck and skill games. Nothing in their responses suggested that they recognized characteristics of the two games that would make success on one more difficult than on the other. For example, 7-year-old Shelby ${ }^{1}$ gave the following responses:

I: Do you think both girls could have gotten their beanbag in the right basket?

S: Yes.

I: What if they tried harder or were more careful?

S: If they concentrated better they could have gotten them in.

I: So could Beth [luck] have gotten the beanbag in the right basket if she had tried harder?

S: Yes.

I: How can you tell?

S: If you concentrate you can do it.

I: Could Peggy have gotten the beanbag in the right basket if she had tried harder?

S: Yes.

I: How can you tell?

S: If you concentrate you can do it.

I: If Beth and Peggy both play their games again and try their hardest, which girl will most likely get the beanbag in the right basket?

S: Beth, because if she concentrated she would get it in ... but I think they both would get it in.

I: And why do you think that?

S: Because they would concentrate and try hard.

Shelby is a firm believer in the power of hard work and concentration, and she gives no indication of recognizing that the luck game would be more difficult than the skill game. The same view was reflected by 5-year-old Marlon:

I: Do you think both boys could have gotten their beanbag in the right basket?

M: Yes.

I: What if they tried harder or were more careful?

M: They would have gotten them in. article.

'Pseudonyms, rather than the participants' actual names, are used throughout the 
I: So could Max [luck] have gotten the beanbag in the right basket if he had tried harder?

M: Yes, because if you get it in the right basket it means that you've been careful.

I: Could Dale [skill] have gotten the beanbag in the right basket if he had tried harder?

M: Yes.

I: How can you tell?

M: Because if you get it in the right basket that means you've been careful.

I: If Dale and Max both play their games again and try their hardest, which boy will most likely get the beanbag in the right basket?

M: Max [luck].

I: And why do you think that?

M: Because he might be more careful.

I: Why do you think Max might be more careful?

M: I just do.

Like Shelby, Marlon advocates using care in throwing the beanbag as an optimal strategy in achieving success, but at no point does he acknowledge that the luck game would be more difficult than the skill game. Children at Level 1 indicated that the probability of achieving success on the luck and skill games was equal.

Level 2. At Leve1 2, children recognized that the luck game was more difficult because the participant had to throw the beanbag before drawing the card. In essence, they realized that the luck game was harder, but they still believed that effort would help a youngster be successful at playing the luck game.

Seven-year-old Kristen was one of the children who displayed reasoning characteristic of a Level-2 understanding of luck and ability:

I: Do you think both girls could have gotten their beanbag in the right basket?

K: Yeah.

I: What if they tried harder or were more careful?

$\mathrm{K}$ : They probably could have got them in if they tried harder.

I: So could Beth [luck] have gotten the beanbag in the right basket if she had tried harder?

K: Yeah.

I: How can you tell?

K: It's easier to do it if you try hard.

I: Could Peggy [skill] have gotten the beanbag in the right basket if she had tried harder?

K: Yeah.

I: How can you tell?

$\mathrm{K}$ : It's easier if you know how and try really hard. I think she could have got it right.

I: If Beth and Peggy both play their games again and try their hardest, which girl will most likely get the beanbag in the right basket?

K: Peggy [skill].

I: And why do you think that?

$\mathrm{K}$ : It's really hard to tell which card is coming [for Beth], but Peggy knows which basket to throw the beanbag at. 
Kristen recognizes the difference in difficulty between the two games but is still convinced that Beth could be successful if she simply tried harder. Sevenyear-old Luke shared this view:

I: Do you think both boys could have gotten their beanbag in the right basket?

L: Yeah.

I: What if they tried harder or were more careful?

L: Yes. They would have gone in.

I: So could Max [luck] have gotten the beanbag in the right basket if he had tried harder?

L: Yeah.

I: How can you tell?

L: Because he could have done major brainstorming.

I: What do you mean by major brainstorming?

L: He could have tried really hard to think about what the card would be.

I: Could Dale [skill] have gotten the beanbag in the right basket if he had tried harder?

L: Definitely!

I: How can you tell?

L: If he was standing straight instead of diagonal he could get it in.

I: If Dale and Max both play their games again and try their hardest, which boy will most likely get the beanbag in the right basket?

L: Dale.

I: And why do you think that?

L: Because he drew the card first. He knows which one to aim for. Max doesn't know which basket to aim for.

Luke seems to be a proponent of Norman Vincent Peale's "power of positive thinking." He clearly believes that Max could be successful if he would give his best effort to thinking about what card in the deck would be drawn next. Even though Max could be successful, Luke recognizes that Dale's task is easier because he has the advantage of drawing the card before he must throw the beanbag, and perhaps making minor technical adjustments to his stance would be helpful. This line of reasoning was typical for children at Level 2.

Level 3. Level 3 is a transitional period in which children display a mature understanding of luck and ability (i.e., Level 4), yet their reasoning is not maintained throughout the complete interview. That is, at some point their reasoning reverts back to Level 1 or 2 . Cindy, 8 years old, demonstrated this transitional level of understanding of luck and ability:

I: Do you think both girls could have gotten their beanbag in the right basket?

C: Yeah.

I: What if they tried harder or were more careful?

C: Yes, they could have done it.

I: So could Beth [luck] have gotten her beanbag in the right basket if she had tried harder?

C: No, well, ... see it depends on what the card is. She might not get it in the right basket if she tried hard, so trying hard probably wouldn't help, ... but it might help.

I: How might trying hard help Beth? 
C: Well, I don't really think it would, . . but it might help her choose the right basket.

I: And could Peggy [skill] have gotten the beanbag in the right basket if she had tried harder?

C: Yes.

I: How can you tell?

C: You know what color basket to put it in with this game, and so she could probably get it in the right one.

I: If Beth and Peggy both play their games again and try their hardest, which girl will most likely get the beanbag in the right basket?

C: Peggy [skill].

I: And why do you think that?

C: Because she knows the color she's supposed to put it in and Beth doesn't.

Cindy seems on the verge of strongly distinguishing luck and ability when she acknowledges that effort will not help Beth perform better on the luck game, but then she reveals uncertainty in her response by adding that effort might help Beth. Cindy's reasoning doesn't quite reflect Level 4, but it's beyond the scope of Level 2, because at Level 2, children recognize the skill game as being easier than the luck game, but they maintain that effort will help participants perform better on both. Cindy notes that "she [Beth] might not get it in the right basket if she tried hard, so trying hard probably wouldn't help," yet her response lacks confidence when she adds that effort might help. She seems to think that effort won't help Beth, but she is not quite willing to go out on a limb and state her view. She leaves open the possibility that effort might help Beth, and her responses provide a good example of the cognitive processing characteristic of children rated at Level 3. Twelve-year-old Caleb's responses also provide an example of this reasoning:

I: Do you think both boys could have gotten their beanbag in the right basket?

C: Yes.

I. What if they tried harder or were more careful?

C: Yes.

I: So could Max [luck] have gotten the beanbag in the right basket if he had tried harder?

C: No. I mean, I doubt it. He won't know which basket to aim for, so trying hard probably won't help. ... I guess if he tried real hard to think about which basket to aim for he might have gotten it in.

I: So if Max had tried harder he might have gotten it in the right basket?

C: Well, I doubt it, but he might have.

I: Could Dale [skill] have gotten the beanbag in the right basket if he had tried harder?

C: Yes.

I: How can you tell?

C: He would know which one [basket] he's throwing at. He would know which color to aim at.

I: If Dale and Max both play their games again and try their hardest, which boy will most likely get the beanbag in the right basket?

C: Dale.

I: And why do you think that?

C: He would know which color to aim at. 
Caleb, like Cindy, expresses doubt in the power of effort to enhance performance on the luck game, but he is not $100 \%$ confident that effort won't help. His responses exceed the reasoning characteristic of Level 2, but they fall short in terms of consistently reflecting Level-4 reasoning.

Level 4. At Level 4, children displayed a strong understanding of the concepts of luck and ability. They realized that high effort would maximize performance on a skill task but not on a luck task. They understood that effort does not affect performance on a luck task. Spencer, a 12-year-old participant, revealed a mature understanding of luck and ability:

I: Do you think both boys could have gotten their beanbag in the right basket?

S: Yeah.

I: What if they tried harder or were more careful?

S: Yeah.

I: So could Max [luck] have gotten the beanbag in the right basket if he had tried harder?

S: No. It really depends on luck. It doesn't matter what basket you aim at because the card has to be right. Trying hard wouldn't help on this game.

I: Could Dale [skill] have gotten the beanbag in the right basket if he had tried harder?

S: Yes.

I: How can you tell?

S: He can just aim real good next time.

I: If Dale and Max both play their games again and try their hardest, which boy will most likely get the beanbag in the right basket?

S: Dale.

I: And why do you think that?

S: This game [Max's] depends on luck. No matter how hard you try you might not get it in. But with this game [skill] you can try hard and get it in.

Spencer understands that effort is not likely to affect the outcome on the luck game, but it will optimize performance on the skill game. His mature understanding of luck and ability was shared by 11 -year-old McKenzie:

I: Do you think both girls could have gotten their beanbag in the right basket?

M: Peggy could have, She knew which basket to aim for.

I: So do you think if Peggy [skill] had tried harder or were more careful she could have gotten her beanbag in the right basket?

M: Yes, because she knew which basket to aim for.

I: What about Beth [luck]? Could she have gotten the beanbag in the right basket if she had tried harder?

M: No. She didn't know where to aim. She had a 1-in-4 chance of getting it in. Trying hard wouldn't help her.

I: If Beth and Peggy both play their games again and try their hardest, which girl will most likely get the beanbag in the right basket?

M: Peggy [skill]. She knew which one to throw to. Beth [luck] had a lot of chances to miss and get the wrong basket.

McKenzie, like Spencer, recognizes that the odds are against the player of the luck game: There is a small chance that he or she will choose the correct card. Trying hard will not help the player choose the correct card or know at which 
basket to aim. Only in the skill game will hard work benefit the participant. Children rated at Level 4 in their understanding of luck and ability quickly picked up on the luck and skill aspects of the games.

\section{Quantitative Analyses of Children's Levels of Understanding of Luck and Ability}

The first independent rater achieved $92 \%$ agreement with the investigator in the rating of all 144 students' responses about their understanding of luck and ability. The other two independent raters achieved $88 \%$ agreement in their ratings (i.e., with one another and with the investigator) of 25 randomly chosen responses from the children in regard to their understanding of luck and ability. This high percentage of agreement reflects strong interrater reliability. Disagreements on ratings were resolved via discussion.

A nonparametric test of association revealed a positive and significant relationship between children's age and their level of understanding of luck and ability (Spearman rho $=.73, p<.001$ ). Table 1 presents the frequency and percentage data for children's ages and their levels of understanding of luck and ability. Over $75 \%$ of the children aged 5-6 years demonstrated Level-1 reasoning of luck and ability. Level-2 reasoning was prevalent among the 8- to 11-year-olds. Half the children rated at Level 3 were 9 and 10 years old, and most of the children aged 12 and 13 years demonstrated Level-4 reasoning of luck and ability.

Examination of the frequency with which youngsters cited luck and ability as contributors to these outcomes revealed consistent age-related differences. A Kruskal-Wallis one-way analysis of variance by ranks test verified the existence of these differences, $\chi^{2}(8, N=144)=78.86, p<.001$. A follow-up multiple-comparisons test (Conover, 1980) was conducted to examine the significant differences between the age groups, and results are presented in Table 2. In general, the

Table 1 Row Frequencies (Percentages) for Age and Level of Understanding of Luck and Ability

\begin{tabular}{|c|c|c|c|c|c|c|c|c|}
\hline \multirow[b]{2}{*}{ Age } & \multicolumn{8}{|c|}{ Level of Understanding of Luck and Ability } \\
\hline & & 1 & & 2 & & 3 & & 4 \\
\hline 5 & 14 & $(88 \%)$ & 2 & $(12 \%)$ & 0 & $(0 \%)$ & 0 & $(0 \%)$ \\
\hline 6 & 12 & $(75 \%)$ & 4 & $(25 \%)$ & 0 & $(0 \%)$ & 0 & $(0 \%)$ \\
\hline 7 & 7 & $(44 \%)$ & 8 & $(50 \%)$ & 0 & $(0 \%)$ & 1 & $(6 \%)$ \\
\hline 8 & 4 & $(25 \%)$ & 11 & $(69 \%)$ & 1 & $(6 \%)$ & 0 & $(0 \%)$ \\
\hline 9 & 4 & $(25 \%)$ & 9 & $(56 \%)$ & 3 & $(19 \%)$ & 0 & $(0 \%)$ \\
\hline 10 & 1 & $(6 \%)$ & 7 & $(44 \%)$ & 4 & $(25 \%)$ & 4 & $(25 \%)$ \\
\hline 11 & 0 & $(0 \%)$ & 10 & $(63 \%)$ & 2 & $(13 \%)$ & 4 & $(25 \%)$ \\
\hline 12 & 1 & $(6 \%)$ & 4 & $(25 \%)$ & 2 & $(13 \%)$ & 9 & $(56 \%)$ \\
\hline 13 & 0 & $(0 \%)$ & 3 & $(19 \%)$ & 2 & $(13 \%)$ & 11 & $(69 \%)$ \\
\hline Total & 43 & $(30 \%)$ & 58 & $(40 \%)$ & 14 & $(10 \%)$ & 29 & $(20 \%)$ \\
\hline
\end{tabular}

Note. $n=16$ for each age. 
Table 2 Mean Sum of Squares Differences in Levels of Understanding of Luck and Ability by Age Group

\begin{tabular}{|c|c|c|c|c|c|c|c|c|c|}
\hline & 5 & 6 & 7 & 8 & 9 & 10 & 11 & 12 & 13 \\
\hline 5 & - & 6.32 & 25.69 & 33.82 & 38.32 & 64.41 & 63.07 & 77.88 & $88.22 *$ \\
\hline 6 & & - & 19.37 & 27.50 & 32.00 & 58.09 & 56.75 & 71.56 & $81.90^{*}$ \\
\hline 7 & & & - & 8.13 & 12.63 & 38.72 & 37.38 & 52.19 & $62.53^{*}$ \\
\hline 8 & & & & - & 4.50 & 30.59 & 29.25 & 44.06 & $54.40^{*}$ \\
\hline 9 & & & & & - & 26.09 & 24.75 & 39.56 & $49.90^{*}$ \\
\hline 10 & & & & & & - & -1.34 & 13.47 & 23.81 \\
\hline 11 & & & & & & & - & 14.81 & 25.15 \\
\hline 12 & & & & & & & & - & 10.34 \\
\hline 13 & & & & & & & & & - \\
\hline
\end{tabular}

Note. $n=16$ for each age group.

*significant differences among respective age groups.

5- to 7-year-old participants were significantly different from the 13-year-olds in their levels of understanding of luck and ability.

A Kruskal-Wallis one-way analysis of variance by ranks test was used to examine potential gender differences in terms of children's levels of understanding of luck and ability. The chi-square statistic indicated no significant gender differences, $\chi^{2}(1, N=144)=.221, p=.64$.

\section{Analyses of Youngsters' Preferences for the Luck and Skill Games}

When children were given the opportunity to play the games for a 5-min period, data for four variables were collected. Specifically, the actual time the youngsters spent playing each game was monitored, and at the end of the $5 \mathrm{~min}$ the youngsters were asked to identify the game they spent the most time playing, the game they thought was the most fun, and the game they would choose to play if an opportunity arose in the future. The data for the participants' behavior or responses for each of the four variables were coded into three categories: (a) luck game (i.e., the child spent more time playing the luck game), (b) skill game (i.e., the child perceived that he or she had spent more time playing the skill game), or (c) both games equally (i.e., the child indicated that both games were equally fun). A frequency count was calculated for the participants' responses to the four variables and is presented based on the ratings of the youngsters' levels of understanding of luck and ability (see Table 3).

It should be noted that the time the children actually spent playing the games could have been treated as a continuous variable, although this was problematic because of the nature of the task. For example, many of the youngsters took turns playing the luck and skill games during the entire $5 \mathrm{~min}$, and when this occurred the investigator entered 2-1/2 min per game. However, a participant could have spent more time on one of the games as a result of a technicality (he or she dropped a beanbag and had to retrieve it before tossing it, time ran out before a turn could 
Table 3 Level-4 Children's Perceptions of the Skill and Luck Games

\begin{tabular}{|c|c|c|c|c|c|c|}
\hline \multirow{3}{*}{$\begin{array}{l}\text { Variable } \\
\text { Actual tim }\end{array}$} & \multicolumn{6}{|c|}{ Game Preferences } \\
\hline & \multicolumn{2}{|c|}{ Luck } & \multicolumn{2}{|c|}{ Skill } & \multicolumn{2}{|c|}{ Tie/No preference } \\
\hline & & & & & & \\
\hline Level 1 & 17 & $(41 \%)$ & 11 & $(26 \%)$ & 14 & $(33 \%)$ \\
\hline Level 2 & 13 & $(22 \%)$ & 27 & $(47 \%)$ & 18 & $(31 \%)$ \\
\hline Level 3 & 2 & $(14 \%)$ & 8 & $(57 \%)$ & 4 & $(29 \%)$ \\
\hline Level 4 & 6 & $(21 \%)$ & 13 & $(45 \%)$ & 10 & $(34 \%)$ \\
\hline \multicolumn{7}{|c|}{ Perceived time } \\
\hline Level 1 & 21 & $(50 \%)$ & 17 & $(40 \%)$ & 4 & $(10 \%)$ \\
\hline Level 2 & 11 & $(19 \%)$ & 32 & $(55 \%)$ & 15 & $(26 \%)$ \\
\hline Level 3 & 2 & $(14 \%)$ & 7 & $(50 \%)$ & 5 & $(36 \%)$ \\
\hline Level 4 & 6 & $(21 \%)$ & 17 & $(58 \%)$ & 6 & $(21 \%)$ \\
\hline \multicolumn{7}{|l|}{ Fun } \\
\hline Level 1 & 17 & $(40) \%$ & 21 & $(50 \%)$ & 4 & $(10 \%)$ \\
\hline Level 2 & 24 & $(41 \%)$ & 25 & $(43 \%)$ & 9 & $(16 \%)$ \\
\hline Level 3 & 7 & $(50 \%)$ & 5 & $(36 \%)$ & 2 & $(14 \%)$ \\
\hline Level 4 & 11 & $(39 \%)$ & 13 & $(47 \%)$ & 4 & $(14 \%)$ \\
\hline \multicolumn{7}{|l|}{ Next time } \\
\hline Level 1 & 16 & $(37 \%)$ & 25 & $(58 \%)$ & 2 & $(5 \%)$ \\
\hline Level 2 & 23 & $(40 \%)$ & 31 & $(54 \%)$ & 3 & $(5 \%)$ \\
\hline Level 3 & 10 & $(71 \%)$ & 4 & $(29 \%)$ & 0 & $(0 \%)$ \\
\hline Level 4 & 11 & $(38 \%)$ & 18 & $(62 \%)$ & 0 & $(0 \%)$ \\
\hline
\end{tabular}

Note. Cell numbers represent row frequencies and percentages, respectively. The first variable refers to the actual amount of time the participants spent playing each game. The other variables refer to the participants' responses to the following 3 questions: "Which game did you spend more time playing?", "Which game do you think is more fun?", and "Which game would you choose to play if you came back on another day?"

be completed, etc.) even though he or she took turns playing each game during the entire $5 \mathrm{~min}$. In addition, it was rather arbitrary for the investigator to determine the point at which the child should be scored as playing one game versus the other game (e.g., at the point that a participant drew a card, began to take aim for the basket, completed a throw, etc). For this reason, the actual time that children spent playing the games was coded into three categories: (a) longer period spent playing the luck game, (b) longer period spent playing the skill game, or (c) equal time spent playing both games. Children who took turns playing the games for the entire $5 \mathrm{~min}$ were categorized as spending equal time on both games. Analysis of the categorical data assessing the actual (i.e., as measured by the investigator) and perceived amount of time (i.e., as assessed by the participants) that the youngsters spent playing the games revealed $80 \%$ agreement for the youngsters aged 8-13 years and $58 \%$ agreement for the 5- to 7-year-olds between the actual and perceived time spent playing the games. 
It was particularly interesting to see which of the games children rated at Level 4 perceived that they played more, was more fun, and that they would prefer to play on another day. The children who were rated at the lower levels of understanding of luck and ability did not yet distinguish the concepts, and so no consistent pattern would be expected in terms of their preferences and perceptions of the luck and skill games. However, because of the Level-4 children's mature understanding of luck and ability, they would as an overall group be expected to prefer the skill game, and results in general supported this hypothesis. Following is a summary of the frequency-count results for each of the four levels of understanding of luck and ability, as well as sample transcriptions of representative responses from participants at each level.

Level 4. Most of the children perceived that they spent more time on the skill game, reported it as being more fun, and indicated that they would choose the skill over the luck game to play if given another opportunity in the future. In addition, the greater percentage of participants rated at Level 4 actually spent more time on the skill task. These results support Nicholls' developmental predictions, in that as a group, youngsters with a mature understanding of luck and ability would prefer the skill task because they understand that they have more control over the outcome on the skill game, they realize that effort could affect their performance on the skill game, and they would be more inclined to become bored with a task (i.e., luck game) that provides them little autonomy. Many of the participants' responses to the questions reflected these views and included the following:

13-year-old girl: "With this game [skill] you have more of a chance of getting it in the bucket. I think games are more fun when you know what you're trying to get or do. This game [skill] was more fun because you have control over the score."

13-year-old boy: "I liked this one [skill game] better. You knew what you had to get so you had more chances to get it right. You knew what you had to do to win and that made it more challenging. That game [points to luck game] was kind of boring. You never knew if you were aiming at the right basket."

12-year-old boy: "I wanted to see how well I could put it in a basket I was aiming for instead of guessing at. I wanted to challenge myself and see how well I could improve."

These responses support Nicholls' predictions that children at Level 4 recognize the differences in tasks requiring luck versus skill and prefer to expend their efforts on activities that challenge their skills. Some participants in the study, however, reflected a mature understanding of luck and ability but indicated their preference for the luck game. These youngsters perceived the skill game as being easy and lacking challenge. They recognized the chance aspect of the luck game but found it novel and interesting, moreso than the skill game. The following quotes from participants highlight this view: 
12-year-old girl: "I liked this game [luck] better. It was fun to see if you could get it right, you know, to see if you have good luck."

12-year-old boy: "This game [luck] is more challenging. You had to guess and I kind of liked having to guess instead of knowing. It's more of a guessing game instead of seeing how skilled you are. You get more satisfaction out of winning this game [luck]. You don't know when you'll win until you turn the card over."

These youngsters clearly distinguished the concepts of luck and ability (i.e., in their earlier responses to the scenarios), yet they perceived the luck game as adding the element of suspense and excitement. One limitation of the games used in this study is that the beanbag-throwing task might have been perceived as more appropriate for children in the lower elementary grades. For older children, the skill game perhaps appeared to be too easy and, therefore, lacking in challenge.

Level 3. The youngsters rated at Level 3 showed a glimpse of fully distinguishing luck and ability, but their reasoning was inconsistent and reflected some aspects of the logic that is characteristic of Levels 1 and/or 2 . As such, it was difficult to predict their responses when they played the luck and skill games. Results revealed that most youngsters rated at Level 3 perceived that they had spent, and actually did spend, more time playing the skill game but perceived that the luck game was more fun and indicated that they would prefer to play that game in the future if the opportunity availed itself. A sample of their responses includes the following:

9-year-old boy: "Well, I was kind of keeping score and I wanted to know how I did. I got six right and four wrong on this game [skill] and six wrong and four right on this game. I thought this one [luck game] was the most challenging. This one [skill game] was okay but a little boring."

10-year-old girl: "I played them [the games] the same amount of time because I just wanted to see which one I was better at. I'm probably better at the one where you threw the beanbag and then draw the card [luck game]. It's easier for me. This game [luck] is a little more fun because I liked to see which one I could get right."

These responses reflect Nicholls' predicted variability in the responses of youngsters rated at Level 3 because of the transitional nature of their reasoning. At some point in the interview, they reflect reasoning characteristic of Level 4 , but they also respond with comments that reflect Level-1 and/or -2 reasoning. As a result, their preferences for luck versus skill tasks could be and were quite variable.

Level 2. The frequency counts for the children rated at Level 2 revealed responses similar to those of participants rated at Level 4 in their understanding of luck and ability. The main difference that could be detected from these two groups was the rationale that they provided for their answers. Typical comments made by children at Level 2 indicated that they perceived the luck game as being more difficult than the skill game but felt that effort would enhance performance on both games. Their responses included the following: 
7-year-old girl: "I played this game [skill] longer, but I don't know why. This game [skill] was more fun because I knew which one I was going to throw to. I wasn't a very good thrower in that one [luck game], but on that one [skill game] I was a good thrower. I got only one [point] on that one [luck game], but I got six or seven [points] on that one [skill game]."

8-year-old boy: "I played this one longer [luck game] because I like harder games. It was more fun because you had to think, and sometimes you'd get it right and sometimes you'd get it wrong, and it would be a lot harder."

8-year-old boy: "I just liked it [skill game] the best. It was fun because you get to turn over the card first and then throw, and it's easier. I played that game [skill] the longest, and I liked it the best."

Evident in the children's responses is their recognition of the different characteristics (luck vs. skill) of the games. They understand that success on the luck game is more difficult to achieve because of the aspect of chance, but their responses do not reflect the fact that effort does not aid performance on the luck task. Of concern are the views stated by some children that they are not very good throwers (i.e., on the luck game) and the perception that the skill game is "easier" and less challenging.

Level 1. Children rated at Level 1 perceived that they had and actually did spend more time playing the luck game but indicated that the skill game was more fun and the one they would prefer to play in the future. Many of their comments suggested that they made very little distinction between the two games:

5-year-old girl: "I just wanted to keep playing this game [luck] until I got a pink one right."

6-year-old boy: "This game [luck] is fun because you can stand anywhere. It's fun because you can stand anywhere and get a bunch of points. I'd play this game [skill] next time because I got it in a bunch, I want to try that game again [luck], but I got more points on that one [luck game]."

The responses of the children rated at Level 1 did not address the luck-versusskill aspects of the games. Instead, the youngsters were more likely to identify factors not associated with the luck and skill characteristics of the games. These results are consistent with Level-1 children's inability to distinguish between tasks requiring luck and skill. These youngsters, then, did not recognize the unique characteristics of the respective games.

\section{Discussion}

This study was the first to use Nicholls' developmental framework to examine youngsters' understanding of luck and ability in the physical domain. Results revealed that the four levels of differentiation of luck and ability identified by Nicholls and Miller (1985) in the academic domain were appropriate for use in the physical domain. Both the qualitative and quantitative analyses suggested a strong 
relationship between the participants' ages and their levels of understanding of luck and ability. In addition, the timing at which the youngsters progressed through the levels was similar to that reported by Nicholls and Miller. For example, most kindergarten children in Nicholls and Miller's study were rated at Level 1 (i.e., $55 \%$ ), as were most 5- and 6-year-olds in the present study (i.e., $81 \%$ ). Nicholls and Miller found that $90 \%$ of the sixth graders in their study demonstrated Level4 reasoning, whereas $63 \%$ of the children 12 and 13 years old were rated at Level 4 in this study. These findings are quite similar to patterns of reasoning levels found in research conducted by Nicholls $(1989,1990)$. More critical, he explained, is the consistent finding that the levels are developmental and structural in nature, in that children progress from one level to the next; these factors are important in revealing the cognitive processes that children display across the childhood years.

It is interesting to note how late children are in distinguishing the concepts of luck and ability. For example, only $63 \%$ of the 12- to 13 -year-old children in this study demonstrated a mature understanding of ability. Nicholls had predicted that for children, this differentiation of luck and ability would come after mature development of the other two concepts (i.e., effort and ability, and task difficulty), based on Piaget's description of the complexity of understanding the probability of particular events occurring. For example, Piaget (1952) explained that in order to understand the concept of luck, children must be able to recognize the relatively low odds of a natural disaster striking, and this requires greater life experience than is typical for young children. Although considerable cognitive capability is necessary to comprehend the distinction between luck and ability, it was still fascinating and surprising to observe in the interviews that approximately $35 \%$ of the children aged 12-13 years sincerely believed that trying harder to think about what color the next card in the deck would be would positively affect the outcome on the luck game. Many coaches and teachers might not be aware of this rate of development of youngsters in terms of their ability to differentiate luck and ability.

Children's understanding of luck and ability was the third and final aspect of the developmental component of Nicholls' theory to receive attention in the physical domain. Results from the present study complement those relating to children's understanding of effort and ability (Fry \& Duda, 1997) and task difficulty (Fry, in press). Fry and Duda found that $63 \%$ of the 13-year-old participants in their study demonstrated a mature understanding of effort and ability (i.e., were rated at Level 4 ), and $75 \%$ of the 5- to 6-year-olds were rated at Level 1 . In addition, $79 \%$ of children aged 8-13 years revealed a complete understanding of task difficulty (were rated at Level 3; Fry). Nicholls (1989) predicted that children would acquire an understanding of task difficulty before distinguishing luck and effort from ability, because the latter concepts require a higher level of cognitive reasoning to grasp. It is understandable that the development of a mature conception of ability would include the simultaneous interaction of these important constructs. Overall, the results from the Fry and Duda study and the Fry study, along with those of this study, suggest strong developmental trends in children's ability to differentiate the concepts of luck, effort, task difficulty, and ability.

Although the primary purpose of this study was to examine participants' levels of understanding of luck and ability, the merits of the research design were further supported by the link between the children's ratings and their preferences for the skill and luck games. Specifically, after being given the opportunity to try the luck and skill games, children who demonstrated a mature understanding of 
luck and ability (i.e., were rated at Level 4) indicated that they spent more time playing the skill game, thought the skill game was more fun, and would prefer to play it in the future if the opportunity availed itself. Both the frequency counts and the specific verbal responses of the youngsters reinforced the differentiated classification they received. It makes intuitive sense that individuals who distinguish the concepts of luck and skill would prefer to participate in a game that involves a greater degree of skill than luck, because it would allow them to optimize their chances of performing well. One need only look at the best-selling games for children to see that younger children are entertained by games with a high luck component (e.g., Candyland, Chutes \& Ladders), probably because the simple requirements of taking turns, drawing a card and following instructions, and counting spaces to move the game pieces provide adequate challenge. As children age they are more inclined to prefer games that include a skill component (e.g., checkers, Monopoly, Parcheesi), perhaps because a more optimal challenge is needed to make participation in games enjoyable and interesting.

Although there was support for the hypothesis that participants rated at Level 4 would prefer the skill over the luck task, there were also a number of youngsters who indicated their preference for the luck game. This finding might have something to do with their perceptions that the beanbag-throwing task was rather elementary for their age. As highlighted in the Results section, some children commented on the simplicity and lack of challenge of the skill game. The decision to use the beanbag-throwing task with baskets in this study was given careful consideration. It was both preferred and difficult to choose a task that was appropriate for a range of participants including 5- to 13-year-old children and adolescents. It would have been problematic to use different tasks when attempting to compare youngsters' ability to reason about luck and ability, and the pilot study suggested that the games were adequate for participants in the age range of those included in the study. It was interesting that children who commented on the ease and simplicity of the skill game for the most part did not have high success rates. That is, although they thought the game looked easy, their actual performance on the game left much room for improvement. Even so, it would have been beneficial for some of the older children to perceive the games as more sophisticated.

Examining the link between children's levels of understanding of luck and ability is an important area of inquiry. Nicholls believed that children's development of a mature understanding of luck and ability might bring with it some benefits that do not accompany a mature understanding of effort and ability and of task difficulty. He suggested, for example, that children who are unable to differentiate luck and skill might find themselves spending more time on activities that require luck and becoming frustrated when they do poorly on luck tasks. In contrast, children who fully distinguish the concepts of luck and skill are likely to spend less time and effort with activities requiring luck (as shown in this study) and might avoid some frustration experienced by younger children whose differentiation of the concepts is less mature.

Evidence of these predictions was observed in the responses of the children while they were playing the respective luck and skill games. A number of children rated at Levels 1 and 2 expressed frustration (e.g., through their words, facial expressions, tone of voice) that they had difficulty performing well on the luck task. A number of these children noted that they were "not very good throwers" when it came to the luck game, lamented the difficulty of the task, and expressed frustration 
at performing poorly. Nicholls predicted that children who were incapable of distinguishing luck and ability might experience negative emotional responses when their high effort on luck tasks resulted in poor performance. Because young children see effort as a primary indicator of ability and performance, it follows that they might grow disenchanted with activities when they observe their high effort resulting in low achievement. A negative emotional response was not expressed by participants rated at Level 4 who preferred the luck game. Rather, these youngsters recognized the luck nature of the task but still enjoyed the chance aspect of the activity.

These results complement Fry's (in press) research examining children's understanding of task difficulty and their personal preferences for difficulty levels. Children rated at Level 3 (i.e., having a mature conception of task difficulty) showed variability in their preferences for easy, moderate, and difficult tasks. Of concern were the $29 \%$ of the youngsters who indicated they would prefer a very easy task that would not challenge them. This hints at the possibility that these youngsters are on the road to developing a strong ego orientation, in which high performance with low effort is sought. Most of the participants, however, indicated that they would prefer a moderate or difficult challenge, which reflects a task orientation, in which high effort is valued. The participants in the study rated at Levels 1 and 2 did not understand the normative nature of the task presented, as was reflected in their preferences for easy, moderate, and difficult tasks. That is, when indicating their preferences for task difficulty, these youngsters did not highlight reasons related to their understanding of normative comparison.

Along the same lines, it was interesting to note the amount of luck experienced by the participants in the present study, particularly those rated at Levels 1 and 2. Their perceptions of the games were affected by their performance, and some of the participants were extremely lucky. One would estimate that youngsters would be successful on the luck game approximately $25 \%$ of the time because of the one-in-four chance they had of choosing the right basket. Some of the children, however, had much higher rates of success on the luck game, and based on their performance even perceived that they were better at the luck game than the skill game. In contrast, some of the children rated at Levels 1 and 2 achieved a much lower success rate than $25 \%$ on the luck game and were more likely to experience frustration because they did not recognize the chance aspect of the luck game. Understandably, the youngsters' perceptions of the games were affected by their performance, and performances were highly variable. This aspect of the study differed from the Nicholls and Miller (1985) study in that they were able to manipulate success and failure on the tasks they employed so that their participants all achieved similar results. Although the participants' performance on the luck tasks would not have influenced their ratings of understanding of luck and ability (i.e., because the interviews took place prior to their playing the games), their performance did, no doubt, affect their perceptions of the luck game. Had performance been manipulated for the participants in this study so that it was consistent for all, there likely would have been less variability in the results observed among youngsters' preferences for the luck game. The advantage of not manipulating the performance outcomes was that the tasks were more similar to real-world experiences. 
The results of these studies examining the developmental component of Nicholls' goal perspective theory are in line with other research reported in the sport psychology literature. For example, researchers (Horn \& Weiss, 1991; McKiddie \& Maynard, 1997; Xiang \& Lee, 1998) have shown that across the school years, children become more accurate at judging their ability. According to Nicholls, this is expected because as children learn to understand important concepts related to achievement (e.g., effort, luck, ability) they acquire the cognitive capacity to more accurately judge their ability. In addition, the literature examining the sources of information that young people use to judge their ability provides support for these developmental constructs. For example, Horn and Hasbrook (1986) reported that young soccer players (i.e., 8- to 9-year-olds) relied more heavily on parent/spectator feedback and game outcomes to judge their success than did older athletes (12- to 13-year-olds). In contrast, the older athletes rated social comparison information as a more important source of information for judging their competence than did the younger athletes. Because younger children are incapable of accurately judging their own or their peers' ability, they would be likely to rely more on the evaluative feedback from significant others (e.g., parents, coaches) to judge their competence.

In conclusion, it is important to note future directions for research involving the developmental component of Nicholls' theory. First, a limitation of the present study is that it employed a cross-sectional rather than longitudinal design. Although the study did provide results that support the developmental component of Nicholls' theory of achievement motivation, future work employing a longitudinal design would supply a richer source of data in that the individual experiences that highlight changes in children's cognitive processing would be more evident. Of interest would be the experiences that prompt children to progress from one level to the next.

Another interesting possibility for future research would be to design a study that examined children's views about luck and ability with regard to the activities in which they currently participated; in the present study, children were brought into a laboratory-type setting and introduced to a game. An approach that might offer additional insight would involve investigating children's understanding of luck and ability in light of the games and sports (e.g., Little League baseball, youth swimming) in which they are currently involved.

Research has now been completed to examine each aspect (i.e., luck and ability, effort and ability, and task difficulty) of the developmental component of Nicholls' theory. Perhaps the most important avenue for future research involves further investigation of the subsequent motivational responses that stem from children acquiring a mature understanding of ability. Previous work (Fry, in press) has revealed that a sizeable number of children who reflected a mature conception of normative task difficulty indicated a preference for engaging in very easy tasks that provide minimal challenge. The present study revealed that children who clearly distinguished luck and ability showed less tendency to become frustrated while playing a luck game in which they had no control over their performance. These findings, however, only begin to scratch the surface in terms of providing a link between mature conceptions of ability and youngsters' motivational responses in achievement settings. There is still much to learn about how the cognitive development of these concepts affects children's experiences in the physical domain. 


\section{Acknowledgment}

This project was funded by a University of Memphis Faculty Research Grant. The author would like to thank George Relyea for his statistical advice and Dr. Bob Brustad and two anonymous reviewers for their helpful comments during the review process.

\section{References}

Conover, W.J. (1980). Practical nonparametric statistics. New York: John Wiley \& Sons.

Duda, J.L., \& Whitehead, J. (1998). Measurement of goal perspectives in the physical domain. In J.L. Duda (Ed.), Advances in sport and exercise psychology measurement (pp. 21-48). Morgantown, WV: Fitness Information Technology.

Fry, M.D. (in press). A developmental examination of children's understanding of task difficulty in the physical domain. Journal of Applied Sport Psychology.

Fry, M.D., \& Duda, J.L. (1997). A developmental examination of children's understanding of effort and ability in the physical and academic domains. Research Quarterly for Exercise and Sport, 68, 331-344.

Fry, M.D., Lattimore, D., \& Balas, C. (1999, September). A developmental analysis of conceptions of effort and physical ability among underserved youth. Paper presented at the annual meeting of the Association for the Advancement of Applied Sport Psychology, Banff, Ontario.

Horn, T.S., \& Hasbrook, C. (1986). Informational components influencing children's perceptions of their physical competence. In M. Weiss \& D. Gould (Eds.), Sport for children and youth: Proceedings of the 1984 Olympic Scientific Congress (pp. 8188). Champaign, IL: Human Kinetics.

Horn, T.S., \& Weiss, M.R. (1991). A developmental analysis of children's self-ability judgments in the physical domain. Pediatric Exercise Science, 3, 310-326.

McKiddie, B., \& Maynard, I.W. (1997). Perceived competence of schoolchildren in physical education. Journal of Teaching in Physical Education, 16, 324-339.

Nicholls, J.G. (1992). The general and the specific in the development and expression of achievement motivation. In G.C. Roberts (Ed.), Motivation in sport and exercise (pp. 31-56). Champaign, IL: Human Kinetics.

Nicholls, J.G. (1990). What is ability and why are we mindful of it? A developmental perspective. In R.J. Sternberg \& J. Killigian, Jr. (Eds.), Competence considered. New Haven, CT: Yale University Press.

Nicholls, J.G, (1989). The competitive ethos and democratic education. Cambridge, MA: Harvard University Press.

Nicholls, J.G. (1978). The development of the concepts of effort and ability, perception of academic attainment, and the understanding that difficult tasks require more ability. Child Development, 49, 800-814.

Nicholls, J.G., \& Miller, A.T. (1985). Differentiation of the concepts of luck and skill. Developmental Psychology, 21, 76-82.

Piaget, J. (1952). The origins of intelligence in children. New York: W.W. Norton.

Piaget, J., \& Inhelder, B. (1975). The origin of the idea of chance in children. London: Routledge \& Kegan Paul.

Xiang, P., \& Lee, A. (1998). The development of self-perceptions of ability and achievement goals and their relations in physical education. Research Quarterly for Exercise and Sport, 69, 231-241.

Manuscript submitted: August 27, 1999

Revision accepted: May 3, 2000 
Copyright of Journal of Sport \& Exercise Psychology is the property of Human Kinetics Publishers, Inc. and its content may not be copied or emailed to multiple sites or posted to a listserv without the copyright holder's express written permission. However, users may print, download, or email articles for individual use. 